\title{
Storage and Safe Disposal of Unwanted/Unused and Expired Medicines: A Descriptive Cross-Sectional Survey among Indian Rural Population
}

\author{
Ponnusankar Sivasankaran*, Elmutaz Belah Mohammed, Navamani Ganesan, Raja Durai
}

'Department of Pharmacy Practice, JSS College of Pharmacy, Ooty, The Nilgiris, Tamilnadu, INDIA.

2JSS Academy of Higher Education and Research, Mysuru, Karnataka INDIA.

\begin{abstract}
Objective: Isoniazid (INH) is metabolized by $\mathrm{N}$-acetyl transferase-2 into Background: Over recent years, an increase in the use of pharmaceutical products has been observed. The lack of clear guidelines in India for the patients regarding the safe disposal of unwanted, unused, expired medicines are increasing the risk of accidental poisoning and environmental hazards. Therefore, this study was conducted to investigate the safe storage and disposal of unused and expired medicine by the public among rural and urban Indian population. Methods: This was an observational, prospective cross-sectional survey conducted for one year period from December 2015 to November 2016 and involved a random sample of households. A self-administrated questionnaire was administered to the study participant considering certain inclusion and exclusion criteria. Results: A total of 1000 subjects agreed to participate and responded to the questionnaire. Most of respondents (58.3\%) have unwanted or unused medicines, additionally, the expired medicines were noted to be $29.3 \%$. Furthermore, the major reason for having unwanted or unused and expired medicines at home was $39.2 \%$ expecting its use in future, whereas, the least reason was a change in prescription (5.9\%). Most of respondents $(57.9 \%)$ agreed that pharmacists provided the information regarding proper storage
\end{abstract}

and safe disposal of medicines. The most common method for disposal of household medicines was disposal in the trash $(78.6 \%) .4 \%$ of the participants return unwanted or unused and expired medicines back to the pharmacy. Conclusion: Our study concluded that most of the respondents dispose of medicines unsafely. On the other hand, an appropriate medication disposal greatly impacted by patient education. Therefore, healthcare providers particularly pharmacists are literally better equipped to educate the public and create adequate awareness for proper storage and safe disposal of unwanted or unused and expired medicine.

Key words: Public behavior, Expired medicines, Medicine disposal, Medicines storage, Medicines wastage, Unused/Unwanted medicines.

Correspondence

Dr. Ponnusankar Sivasankaran, Professor and Head, Department of Pharmacy Practice, JSS College of Pharmacy, Ooty - 643001, The Nilgiris, Tamil Nadu, INDIA.

Phone: +91-9489613428

Email: ponnusankarsivas@gmail.com

DOI: 10.5530/jyp.2019.11.20

\section{INTRODUCTION}

Medicines play a vital role in the diagnosis, prevention and treatment of many diseases or medical conditions. ${ }^{1}$ It has been documented that more than half of all medications are inappropriately prescribed, dispensed globally and only $50 \%$ of patients take their medication rationale..$^{2-3}$ Medication adherence is even lower in developing countries. ${ }^{4}$ A study called national Survey on Drug Use and Health (NSDUH) found that over $70 \%$ of people who abused prescription pain relievers got them from friends or relatives; while approximately $5 \%$ of the medicines got them from drug dealers. ${ }^{5}$ Ultimately, unwanted or unused and expired medicines are piling up in homes and ending up in landfills, sewers, streams and water supplies. Prescription drugs accumulate in households often because of patient non-adherence, improvement in treated conditions and medication discontinuation due to changes in dose, drug expiration and patient deaths. However, the self-discontinuation by people was recorded the main reason for increasing the volume of unwanted or unused and expired medicines. ${ }^{6}$

The home medicines cabinets are a source that contributes to prescription drug abuse and drug overdose epidemic. ${ }^{7-8}$ The previous studies revealed that the majority of the population dispose of unwanted or unused and expired medicines in toilets or sink. Consequently, it can lead to a direct impact on the public safety and the environment hazard. ${ }^{9-11}$ Nevertheless, in research carried out by the American Association of Poison Control Centers' (AAPCC) National Poison Data System (NPDS) in 2010 stated that $30 \%$ of the overdose and death were due to accidental ingestion of preparation or over-the-counter medications fatality. ${ }^{12}$ Therefore, this study was conducted to investigate the safe storage and disposal of unused and expired medicine by the public among rural and urban Indian population.

\section{METHODS}

It is a descriptive cross-sectional survey used a pretested self-administered structured questionnaire to collect data from the public of rural and urban areas in Nilgiris district, Tamilnadu, India. The survey questionnaire was validated by conducting a pilot study on 80 randomly selected participants from rural and urban areas to assess the quality of the questionnaire. Upon the result of the pilot study, the questions were modified to ensure the understanding and simplicity. Furthermore, the relevancy of the questionnaire contents was verified. The survey questionnaire consisted with 27 questions was divided into four sections include: 


\section{Demographic}

It represents the demographic details of the respondents' like age, gender, residence area, educational level and occupation.

\section{Pattern of storage}

It determined the pattern of storing the medicines in the home like the kitchen, bedroom, fridge, shelf, boxes, cupboard, depends on the label.

\section{Reasons to store}

It investigated the reasons of keeping excessive unwanted or unused and expired medicines in the home like changes in the prescription, medicine expired, self-discontinuation, expecting future need and medication didn't suit.

\section{Approach to dispose}

It assessed how the participant often chose approach to dispose the unwanted or unused and expired medicines like trash, return to pharmacy, disposal it in a river, toilet or sink, use it as a plant fertilizer, give it to friends, bury the medicines and disposal the medicine in a biomedical waste container.

Earlier the study was approved by the Institutional Ethical Committee, JSS College of Pharmacy, Udhagamandalam (JSS/DPP/IRB/004/2015-16 Date: 05/11/2015). Nevertheless, an oral informed consent was obtained from all the subjects' before getting their responses. The inclusion criteria involved age of 18 years and less than 85 years with an exposure to medicine usage. Participants who are unwilling to respond to the questionnaire, didn't understand the questions, were excluded. An Online sample size calculator (SurveyMonkey) and stratified sampling technique were used to calculate the sample sizes in the study. ${ }^{13}$ The data collected was analyzed using SPSS for Windows, version 21.0, Armonk, NY: IBM Corp and the chi-square test were used to find out the differences.

\section{RESULTS}

A total of 1000 participants completed the questionnaire (83\% response rate) during one year study period from December 2015 to November 2016. Among them, 509 were females (50.9\%) and 491 were males (49.1\%). The majority of the respondents were in between the age group of 31-50 years (44.8\%). Overall 59.9\% of the respondents were employed. Among all the participants 597 (59.7\%) were from the rural residential area, whereas, 403 (40.3\%) were from urban area (Table 1).

The majority of the respondents $(57.1 \%)$ purchased the medicines through the pharmacy. Surprisingly, $58.3 \%$ of the respondents have unwanted or unused and expired medicines at home. Furthermore, the respondents stated that the major reason for having unwanted or unused and expired medicines at home was (39.2\%) expecting its use in future, followed by $(22.8 \%),(20.3 \%)$ expiration of medicines and self-discontinuation, whereas, the least reason was a change in prescription (5.9\%). Predominantly, most of the respondents read the storage directions on the label (73.1\%). Consequently, $64 \%$ of the respondents claimed that they store the medicines as per the storage condition specified in the label. Nonetheless, $88.8 \%$ of the respondents check the expiry date before taking and during storage of medicines (Table 2). Across all the study areas the statistical result showed that the most common method of disposal of unwanted or unused and expired medicines adopted by the respondents were by throwing them into trash (78.6\%), followed by discarding, burning $(6.1 \%)$, disposal in toilet or sink $(3.3 \%)$, used as fertilizers for plants (1.6\%) and throwing it in rivers (0.4\%). Whereas, $4 \%$ of the participant return unwanted or unused and expired medicines to the pharmacy and $0.4 \%$ of them treating it as bio-medical waste (Figure 1 ). A few $0.8 \%$ and $0.6 \%$ of the respondents stated that they had accidental poisoning events occurred due to improper storage and unsafe disposal of medicines respectively. However, it is very interesting that $57.9 \%$
Table 1: Socio-demographic characteristics of respondents from different study areas.

\begin{tabular}{cccc}
\hline $\begin{array}{c}\text { Demographic } \\
\text { data }\end{array}$ & Parameter & $\begin{array}{c}\text { No of } \\
\text { Participants } \\
\mathrm{n}=1000\end{array}$ & Percentage \\
\hline $\begin{array}{c}\text { Gender } \\
\text { distribution }\end{array}$ & Male & 491 & $49.1 \%$ \\
Female & 509 & $50.9 \%$ \\
Age distribution & $>18<30$ & 362 & $36.2 \%$ \\
& $31-50$ & 448 & $44.8 \%$ \\
Education & $51-70$ & 148 & $14.8 \%$ \\
& $>70$ & 42 & $4.2 \%$ \\
& None & 65 & $6.5 \%$ \\
High school & 199 & $19.9 \%$ \\
& $>$ High school & 182 & $18.2 \%$ \\
& Employed & 554 & $55.4 \%$ \\
Residential area & Unemployed & 243 & $59.9 \%$ \\
& Student & 115 & $24.3 \%$ \\
Household & Rural & 597 & $11.5 \%$ \\
members & Urban & 403 & $59.7 \%$ \\
& 2 to 4 & 683 & $40.3 \%$ \\
\hline
\end{tabular}

respondents agreed that pharmacists provided the information regarding proper storage and safe disposal of medicines. Positively, $57.9 \%$ of the respondents aware of improper storage unsafe disposal of medicines harm human health and the environment.

In this study, we examined the association for all the parameters used in the questionnaire by using chi-square test between the residential area of the participants mainly urban and rural population and calculated the odds ratio between urban and rural population. There were significant associations between residential area of the participants and whether or not the participants have unwanted or unused and expired medicines at home; stores and check expiry date as per the storage directions in the label (Table 3).

\section{DISCUSSION}

The present study examined the storage and safe disposal of unwanted or unused and expired medicines by the general public in the Nilgiris district. Accordingly, various reasons were found for storing of unwanted or unused and expired medicines at home such as self-discontinuation due to side effects, expecting future need and changes in prescription were founded to be the most. Many cases were reported around the world, due to accidental exposure to unwanted or unused and expired medicine and its unsafe storage and disposal. Ultimately, it makes a health and safety risk in public health partially children. ${ }^{12}$ The accumulations of unwanted or unused and expired medicines are the result of non-adherence to the recommendations. In our study, the unwanted or unused and expired medicines retention were comparably high than expired medicines at home particularly in participant from rural than urban area. Among the study respondents, many were not aware of the consequences of unsafe disposal of medicines, $\backslash$ and few of them were using the left over or expired medicines for gardening, burning and throwing in a river. However, most of the respondents use trash as the 
Table 2: Assessment of storage pattern of medicines among the study respondents.

\begin{tabular}{|c|c|c|c|}
\hline Parameter & Options & $\begin{array}{c}\text { No of } \\
\text { Participants } \\
n=1000\end{array}$ & Percentage \\
\hline \multirow{4}{*}{$\begin{array}{c}\text { Where do you usually } \\
\text { get your medicines } \\
\text { from? }\end{array}$} & Doctor & 115 & $11.5 \%$ \\
\hline & Pharmacy & 571 & $57.1 \%$ \\
\hline & $\begin{array}{c}\text { Primary healthcare } \\
\text { center }\end{array}$ & 40 & $4 \%$ \\
\hline & Government hospital & 78 & $7.8 \%$ \\
\hline \multirow{2}{*}{$\begin{array}{l}\text { Unwanted/Unused } \\
\text { medicines at home }\end{array}$} & Yes & 583 & $58.3 \%$ \\
\hline & No & 417 & $41.7 \%$ \\
\hline \multirow{3}{*}{$\begin{array}{l}\text { Number of expired } \\
\text { medicines }\end{array}$} & $<5$ & 232 & $23.2 \%$ \\
\hline & $\geq 5$ & 61 & $6.1 \%$ \\
\hline & No & 707 & $70.7 \%$ \\
\hline \multirow{5}{*}{$\begin{array}{l}\text { Reason for unwanted } \\
\text { /unused medicines at } \\
\text { home }\end{array}$} & $\begin{array}{l}\text { Changes in } \\
\text { prescription }\end{array}$ & 59 & $5.9 \%$ \\
\hline & Medicine expired & 228 & $22.8 \%$ \\
\hline & Self-discontinuation & 203 & $20.3 \%$ \\
\hline & $\begin{array}{l}\text { Expecting future } \\
\text { need }\end{array}$ & 392 & $39.2 \%$ \\
\hline & Nil & 59 & $5.9 \%$ \\
\hline \multirow{2}{*}{$\begin{array}{l}\text { Do you read the } \\
\text { storage directions in } \\
\text { the label? }\end{array}$} & Yes & 731 & $73.1 \%$ \\
\hline & No & 269 & $26.9 \%$ \\
\hline \multirow{4}{*}{$\begin{array}{l}\text { Do you store as per } \\
\text { the storage condition } \\
\text { specified in the label? }\end{array}$} & Yes & 640 & $64 \%$ \\
\hline & No & 360 & $36 \%$ \\
\hline & Kitchen & 205 & $20.5 \%$ \\
\hline & Bedroom & 522 & $52.2 \%$ \\
\hline \multirow{4}{*}{$\begin{array}{l}\text { Where do you store } \\
\text { the medicines? }\end{array}$} & Fridge & 95 & $9.5 \%$ \\
\hline & Shelf & 35 & $3.5 \%$ \\
\hline & $\begin{array}{l}\text { Kitchen and } \\
\text { bedroom }\end{array}$ & 20 & $2 \%$ \\
\hline & Boxes & 11 & $1.1 \%$ \\
\hline \multirow{2}{*}{$\begin{array}{c}\text { Accessibility of } \\
\text { medicines for children }\end{array}$} & Yes & 390 & $39 \%$ \\
\hline & No & 261 & $26.1 \%$ \\
\hline \multirow{2}{*}{$\begin{array}{c}\text { Do you check expiry } \\
\text { date before taking } \\
\text { and during storage of } \\
\text { medicines }\end{array}$} & Yes & 888 & $88.8 \%$ \\
\hline & No & 112 & $11.2 \%$ \\
\hline
\end{tabular}

\begin{tabular}{r|r} 
Biomedical waste & $0.40 \%$ \\
River & $0.40 \%$
\end{tabular}

Retun to pharmacy $3.50 \%$

$$
\begin{array}{c|c}
\text { Plant } & 1.60 \% \\
\text { Bury } & 4.20 \%
\end{array}
$$

\begin{tabular}{|c|c|}
\hline \multirow[t]{2}{*}{ Toilet/Sink } & $3.30 \%$ \\
\hline & $6.10 \%$ \\
\hline
\end{tabular}

Give to friends $1.40 \%$

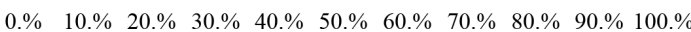

Figure 1: The pattern of disposing of unwanted or unused and expired medicines by the study participants.
Table 3: The influence of the residential area on the respondent attitude

\begin{tabular}{|c|c|c|c|c|c|c|c|}
\hline \multirow{2}{*}{$\begin{array}{c}\text { Parameters } \\
\text { checked }\end{array}$} & \multicolumn{2}{|c|}{ Rural } & \multicolumn{2}{|c|}{ Urban } & \multirow{2}{*}{$\begin{array}{l}\text { Odds } \\
\text { ratio }\end{array}$} & \multirow{2}{*}{$\begin{array}{c}\text { Pearson } \\
\text { Chi- } \\
\text { Square }\end{array}$} & \multirow[t]{2}{*}{$P$ value } \\
\hline & Yes & No & Yes & No & & & \\
\hline $\begin{array}{c}\text { Do you check } \\
\text { the expiry } \\
\text { date? }\end{array}$ & $57.1 \%$ & $80.4 \%$ & $42.9 \%$ & $19.6 \%$ & 3.07 & 22.37 & $p<0.001$ \\
\hline $\begin{array}{l}\text { Do you read } \\
\text { the storage } \\
\text { directions? }\end{array}$ & $40.7 \%$ & $19.0 \%$ & $32.4 \%$ & $7.9 \%$ & 1.91 & 18.279 & $p<0.001$ \\
\hline $\begin{array}{l}\text { Unwanted or } \\
\text { Unused, } \\
\text { and expired } \\
\text { medicines in } \\
\text { home }\end{array}$ & $37.3 \%$ & $22.4 \%$ & $21.0 \%$ & $19.3 \%$ & 1.53 & 10.642 & $p<0.001$ \\
\hline $\begin{array}{l}\text { Do you store } \\
\text { medicines as } \\
\text { per storage } \\
\text { conditions? }\end{array}$ & $33.4 \%$ & $26.3 \%$ & $30.6 \%$ & $9.7 \%$ & 2.48 & 41.703 & $p<0.001$ \\
\hline
\end{tabular}
towards the disposal of unwanted or unused and expired medicines.

(Statistical calculations were carried out using bivariate analysis)

common method for disposal of medications. Similar study reports showed that $54 \%$ of the patients stored the drugs, $52 \%$ disposed in the trash and 35\% flushing in toilets. ${ }^{14-16}$ The consequence of such behaviors are the presence of pharmaceutical products in groundwater, rivers and even in drinking water, which may cause huge environmental hazards.

Unfortunately, we found that there were cases of accidental poisoning events occurred due to improper storage and unsafe disposal of medicines. Predominantly, in this study, we found that there is a role of patient education on the proper disposal of unwanted or unused and expired medications. Moreover, instructions provided by pharmacist can help the people for storage and disposal of the medicines properly, nevertheless, check the expiry date during purchase and storage. Therefore, medicine take-back program is a good approach to safely dispose of unwanted or unused and expired medicines from home. However, pre-counseling by a health care provider on how to properly store, safely dispose of medicines was associated with the more recent visit to the pharmacy. Consequently, it resulted in high probation of returning of unwanted or unused and expired medicines to the pharmacy.

\section{CONCLUSION}

Our study concluded that most of the respondents dispose of medicines unsafely. Therefore, healthcare providers particularly pharmacists are literally better equipped to educate the public and create adequate awareness for proper storage and safe disposal of unwanted or unused and expired medicine. Moreover finding approaches for implementing laws on wastage destruction of the medicines is predominantly demanded.

\section{Limitation}

The survey was conducted only in selected places of The Nilgiris District. Wider survey reaching remote places may reveal further valuable information.

\section{ACKNOWLEDGEMENT}

The authors wish to thank JSS College of Pharmacy, Ooty for providing necessary facilities to carryout this work. 


\section{CONFLICT OF INTEREST}

The authors declare no conflict of interest.

\section{ABBREVIATIONS}

AAPCC: American Association of Poison Control Centers; INH: Isoniazid; NSDUH: National Survey on Drug Use and Health.

\section{REFERENCES}

1. Cranko JA, Sleggs WW. Dutch medicines and their uses, Cent Afr J Med. 1960;6(5):215.

2. Brown M, Sinsky CA. Medication Adherence: We didn't ask and they didn't tell. Fam Pract Manag. 2013;20(2):25-30.

3. Chummun, H, Boland D. How patient beliefs affect adherence to prescribed medication regimens. Br J Nurs. 2013;22(5):270-6.

4. Holloway KA. Combating inappropriate use of medicines. Expert Rev Clin Pharmacol. 2011;4(3):335-48.

5. Back SE, Payne RL, Simpson AN, Brady KT. Gender and prescription opioids: findings from the National Survey on Drug Use and Health. Addict Behav. 2010;35(11):1001-7.

6. Stergachis A. Promoting the proper disposal of unused, unwanted or expired medications. J Am Pharm Assoc. 2014;54(3):226.

7. Thormodsen M, Fonneløp H, Rytter E, Tørisen HM. To be used as directed by your physician"--reasons why patients do not use prescribed medicine. Tidsskr
Nor Laegeforen. 1997;117(24):3521-5.

8. Lindberg MJ, Andersen SE, Christensen HR, Kampmann JP. Compliance to drug prescriptions. Ugeskr Laeger. 2008;170(22):1912-6.

9. Sunita SP, Sunil KP. Critical eye towards storage and disposal of prescribed medicine. GJMEDPH. 2013;2(6):1-5.

10. Amod F, Chetty K, Essa AS, Hlela L, Naharaj C, Oosthuizen F. A pilot study to determine public trends in storage and disposal of medicines. SAPJ. 2008;75(7):6

11. Radhakrishnan L, Prabhu N, Suvidya SV, Thirumalaikolundu SP. Knowledge, attitude and practice (KAP) towards disposal of medicines: a qualitative study among health care professionals in South India. WJPR. 2014;3(6):1955-63.

12. Bronstein AC, Spyker DA, Cantilena LR Jr, Green JL, Rumack BH, Giffin SL. Annual Report of the American Association of Poison Control Centers National Poison Data System (NPDS): $27^{\text {th }}$ Annual Report. Clin Toxicol (Phila). 2010;48(10):979-1178.

13. SurveyMonkey [Internet]. Sample Size Calculator: Understanding Sample Sizes. [Updated 2015 February 25; cited 2015 March 19]. Available from: https://www. surveymonkey.com/mp/sample-size-calculator/

14. Anurag J, Bhatia MS, Srivastava S. Medication errors in clinical practice. Delhi Psy J 2011;14(2):205-10.

15. Tong $A Y$, Peake BM, Braund R. Disposal practices for unused medications around the world. Environ Int. 2011;37(1):292-8.

16. Ruhoy I, Daughton C. Types and quantities of leftover drugs entering the environment via disposal to sewage- revealed by coroner records. Sci Total Environ. 2007:15;388(1-3):137-48.

Article History: Submission Date : 18-05-2018; Revised Date : 03-08-2018; Acceptance Date : 30-10-2018.

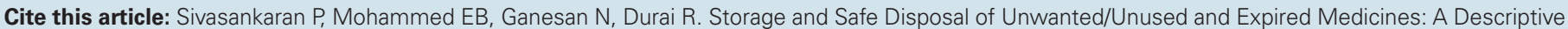
Cross-Sectional Survey among Indian Rural Population. J Young Pharm. 2019;11(1):97-100. 